\title{
The Effectiveness of Flourish Training on Occupational Wellbeing among Trainers of Exceptional Children with Special Needs in Yazd
}

\author{
Hamed Naghashian ${ }^{1}$, Abdozahra Naami², Yadollah Zargar ${ }^{3}$, Kiumars Beshlide4, Nasrin Arshadi ${ }^{5}$ \\ 1,2,4,5 Department of Psychology, Shahid Chamran University of Ahvaz, Ahvaz, Iran. \\ ${ }^{3}$ Department of Counselling, School of Humanities, Hazrat-e Masoumeh University, Qom, Iran.
}

\section{ABSTRACT}

\section{BACKGROUND}

The present study intended to determine the effectiveness of flourish training on occupational wellbeing. The statistical population of this study were trainers of exceptional children with special needs.

\section{METHODS}

Thirty people were randomly selected among this population and then appointed to two experiment and control groups. Pretest-posttest with control group design was used to achieve the objectives of the study. Study instruments included occupational wellbeing, occupational burnout, occupational motivation, and occupational fascination questionnaires (for both groups). Flourish training was performed on the experiment group in 10 sessions, and the post-test was carried out for both groups after the end of the sessions. Then, multivariate analysis tests and SPSS v17 were used to analyse data.

\section{RESULTS}

The results showed that flourish training made a significant difference in all research variables between experiment $(133.6 \pm 33.65)$ and control $(121.8 \pm 80.52)$ groups. It means that the mean of the experiment group has significantly increased compared to the control group, indicating flourish training effectiveness on occupational wellbeing.

\section{CONCLUSIONS}

The results of this study may be used to improve positivism among individuals.

\section{KEY WORDS}

Flourish Training, Occupational Wellbeing, Exceptional Children, Special Needs
Corresponding Author: Dr. Hamed Naghashian, Department of Psychology, Shahid Chamran University of Ahvaz, Ahvaz, Iran.

E-mail: hamednaghashian@yahoo.com

DOI: $10.14260 /$ jemds/2021/790

How to Cite This Article:

Naghashian H, Naami A, Zargar Y, et al. The effectiveness of flourish training on occupational wellbeing among trainers of exceptional children with special needs in Yazd. J Evolution Med Dent Sci 2021;10(45):3910-3914, $10.14260 /$ jemds/2021/790

Submission 21-09-2021,

Peer Review 14-12-2021, Acceptance 20-12-2021, Published 28-12-2021.

Copyright (C) 2021 Hamed Naghashian et al. This is an open access article distributed under Creative Commons Attribution License [Attribution 4.0 International (CC BY 4.0)] 


\section{BACKGROUND}

Psychology has mainly focused on pathology and functional impairment in humans since the 1940s and the beginning of WWII and continuously has considered negative aspects and emotions, such as anxiety and depression. ${ }^{1}$ Humans flourish through applying capacity and talent. ${ }^{2}$ Flourishing describes a high level of mental health by social, mental, and emotional wellbeing. ${ }^{3}$ State that this new branch of psychology mainly studies power, happiness, and mental wellbeing scientifically. ${ }^{4}$ They mention that what is considered in positive psychology and psychological wellbeing is how human life flourishes and his/her potentials turn into action. ${ }^{5}$ Further, they believe that, according to this new approach, any individual with features such as self-esteem, wide social communication, self-efficacy, and independence enjoys mental health or psychological wellbeing. Therefore, various theories and key views have been recently proposed about positive psychology, one of which is flourishing. ${ }^{6}$

Studies about wellbeing have been increased during the past two decades, providing various definitions. ${ }^{7}$ Wellbeing is defined as individuals' mental evaluation of their lives and includes concepts such as life satisfaction, pleasant emotion, fulfilment, and meaningfulness. ${ }^{8}$ It is among the optimal parameters of life since a life without pleasure, emotion, and the sense of satisfaction and meaning and with dissatisfaction and anger may not be ideal. ${ }^{8}$ According to Parker and Hyett, occupational wellbeing is a multidimensional structure including four dimensions of work satisfaction, organizational respect for the employee, employer care, and intrusion of work into private life. ${ }^{9}$

The occupational satisfaction dimension means how much individuals' occupation makes satisfaction, valuableness, and meaningfulness and how it may develop and promote their abilities. ${ }^{10}$ Respect for staff means that how much upper hand individuals of an organization are trustworthy and respect moral values and also how much staff believe and follow the organization's values. Among medical staff, there is a positive relationship between occupational wellbeing and life quality, occupational satisfaction, and occupational performance; also, there is a negative relationship between occupational wellbeing and work-family conflict.11

\section{METHODS}

This research was a pretest-posttest with the control group design. Population included all trainers of exceptional children with special needs in Yazd and sample included 30 trainers of exceptional children with special needs who were selected randomly. Initially, all participants were asked to answer an occupational wellbeing questionnaire. Then, the intervention was applied to the experiment group; finally, the tastes of both groups answered research questionnaires. To conduct the study ethically, all the steps and objectives were described to the participants. Then, a written informed consent form was given to them. Moreover, all necessary explanation concerning the right to withdraw the study for any reason was provided to the participants.

\begin{tabular}{|c|c|c|c|c|c|}
\hline \multicolumn{4}{|c|}{ Follow-up Posttest Intervention Posttest } & Groups & \multirow{2}{*}{$\begin{array}{c}\text { Random selection } \\
R\end{array}$} \\
\hline $\mathrm{T} 3$ & T2 & $\mathrm{X}$ & $\mathrm{T} 1$ & Experiment & \\
\hline T3 & T2 & - & T1 & Control & $\mathrm{R}$ \\
\hline \multicolumn{6}{|c|}{ Pretest-Posttest with Control Group Design } \\
\hline
\end{tabular}

According to the above table, participants were assigned to experiment and control groups randomly. Both groups were pre-tested, post-tested, and followed-up. The experiment group received an intervention; however, the control group did not receive any intervention, and it was only pre-tested, post-tested, and followed-up. It is worth mentioning that one month after experimental intervention, dependent variables were measured as a follow-up. The statistical population included trainers of children with special needs in Yazd.

\section{Inclusion Criteria}

- Work experience of more than 5 years,

- At least a BA degree,

- Not participating in other consultation and psychotherapeutic sessions simultaneously,

- Not using psychiatric drugs.

After examining inclusion criteria for trainers, 30 of them were randomly selected. Then, the experiment group was trained flourishing, and 10 personal flourish training sessions were performed for the control group after performing posttest during follow-up. The flourish training plan consisted of 10 120-minute sessions, with the class consisted of one trainer and one assistant trainer.

\section{Occupational Well-being Questionnaire}

This questionnaire designed by Parker et al. has 31 questions, which include four dimensions of work satisfaction (10 items), organizational respect for the employee (7 items), employer care (7 items), and intrusion of work into the private life (7 items). ${ }^{9}$ Answers are ranged on a five-degree Likert scale from never-1 to very much-5. Question number 26 of this questionnaire is scored reversely. The total score of scale is obtained from the sum of subscales scores, and it is ranged from 31 to 155, with a low score indicating a low level of health and wellbeing of employees in the work environment. Parker uses the retest method to calculate the reliability of this instrument, which is $91 \%$ for work satisfaction, $95 \%$ for organizational respect for the employee, $87 \%$ for employer care, $71 \%$ for the intrusion of work into the private life, and $91 \%$ for the total scale. ${ }^{9}$ This questionnaire has been translated into Persian by Kaabomeir et al and its reliability has been reported $79 \%$ for work satisfaction, $82 \%$ for organizational respect for the employee, $93 \%$ for employer care, and $62 \%$ for the intrusion of work into the private life. ${ }^{12}$

\section{Flourish Training}

The flourish training plan was performed on the experiment group. This program was performed under the titles of tolerance, strength points of personality, and flourishing as a two-day workshop for Singaporean teachers. ${ }^{13}$ The content of medical sessions was in five main intervention fields, 
including positive emotions, relationships, involvement, meaning, and progress, being performed in 10, 2-hour sessions as a follow-up. Also, the sessions were performed as lectures, group discussions, ask-answer, and class activities.

\begin{tabular}{|c|c|}
\hline Sessions & The Content of the Flourish Intervention Training Session \\
\hline Session 1 & $\begin{array}{c}\text { Introducing and familiarizing with the participants and making a } \\
\text { relationship; } \\
\text { Familiarizing participants with subjects, educational purposes, and } \\
\text { positive psychology based on improved resilience, the ABC model } \\
\text { (according to the study by Ellis (1975), indicating that when an activating } \\
\text { event (A) happens, beliefs (B) affect consequences (C) or outcomes in two } \\
\text { ways); } \\
\text { Conclusion }\end{array}$ \\
\hline Session 2 & $\begin{array}{l}\text { Reviewing the contents of the previous session with the help of } \\
\text { participants; } \\
\text { Introducing flourish, positive psychology, thought patterns; } \\
\text { Speaking about thought traps and interventions in views, positive } \\
\text { emotions, love-kindness meditations, and appending positive pieces; } \\
\text { Selecting a positive feeling and making a general plan for } \\
\text { reviewing the contents of the previous session with the help of }\end{array}$ \\
\hline Session 3 & $\begin{array}{l}\text { participants. } \\
\text { Introducing abilities; classifying abilities; focusing on the advantages of } \\
\text { abilities and PERMA elements (positive emotions, engagement, } \\
\text { relationships, meaning, and achievement), emphasizing positive } \\
\text { emotions; activities in class; experiencing positive and negative emotions; } \\
\text { expressing feelings and thoughts }\end{array}$ \\
\hline Session 4 & $\begin{array}{l}\text { Representing a summary of previous session contents; } \\
\text { Introducing engagement, conditions effective on engagement in work, } \\
\text { engagement methods, and group work; } \\
\text { (checking out previous session homework, lecturing about involvement } \\
\text { and release in a pleasurable activity, group exercise, ask-answer about } \\
\text { involvement in a special activity, and checking involvement barriers); } \\
\text { Conclusion }\end{array}$ \\
\hline Session 5 & $\begin{array}{c}\text { Representing a summary of previous session contents; } \\
\text { Lecturing about relationships, relationship-wellbeing, trust-building } \\
\text { activity, trust, and relationship-making strategies; } \\
\text { Conclusion }\end{array}$ \\
\hline Session 6 & $\begin{array}{l}\text { Representing a summary of previous session contents; } \\
\text { Introducing meaning and meaning story; } \\
\text { Lecturing about purpose and meaning in life (a selective of Victor Frankl's } \\
\text { book, Man's Search for Meaning-we have to be responsible to have } \\
\text { meaning and be purposeful in life, as well as believing that we can help } \\
\text { the world around us); } \\
\text { Conclusion }\end{array}$ \\
\hline Session 7 & $\begin{array}{l}\text { Representing a summary of previous session contents; } \\
\text { Introducing the concept of achievement and progression and successful } \\
\text { people's characteristics, ask-answer; } \\
\text { Conclusion }\end{array}$ \\
\hline Session 8 & $\begin{array}{l}\text { Representing a summary of previous session contents; } \\
\text { Introducing resilience and strategies to improve it; } \\
\text { (Resilience does not only mean recovering from a bad event, but it means } \\
\text { precision about misfortune or flexibility for compatibility); } \\
\text { Conclusion }\end{array}$ \\
\hline Session 9 & $\begin{array}{l}\text { A short review on the contents represented during the training course; } \\
\text { asking participants' opinions about the contents; re-performing DASS } \\
\text { scale on both experiment and control groups }\end{array}$ \\
\hline Session 10 & $\begin{array}{c}\text { Closing the group; discussing what has learned; summarizing the } \\
\text { achievements of each participant; emphasizing the positive skills each } \\
\text { person has learned }\end{array}$ \\
\hline
\end{tabular}

\section{Statistical Analysis}

Descriptive indices included mean and standard, and multivariate analysis tests were used. Moreover, IBM SPSS Statistic (version 17) (IBM Corporation, Armonk, NY) was applied for analysis the data.

\section{RESULTS}

Calculating statistical indexes including Mean Difference $(\mathrm{MD}=3)$ and Standard Deviation $(\mathrm{SD}=3)$ in the pilot study and with regarding statistical power of $80 \%(\mathrm{P}<0.05), 30$ patients were needed for two group $(n=30)$.). Thirty people, with an age range of 27 to 39 years, participated in this study (15 in the control group and 15 in the experiment group). All participants received flourish training. Then, the frequency and percentage of groups' members were represented.
According to the Table 1, the mean and SD of study variables were represented considering the groups and test stages. After investigating descriptive findings, inferential results were studied.

\begin{tabular}{|c|c|c|c|c|}
\hline Variables & Group & $\begin{array}{c}\text { Pre-test } \\
\text { (SD } \pm \text { mean) }\end{array}$ & $\begin{array}{c}\text { Post-test } \\
\text { (SD } \pm \text { mean) }\end{array}$ & $\mathbf{P}$ \\
\hline \multirow{3}{*}{ Work satisfaction } & Experiment & $38.3 \pm 93.94$ & $42.2 \pm 80.78$ & \multirow{3}{*}{0.005} \\
\hline & Control & $37.2 \pm 73.89$ & $39.3 \pm 47.83$ & \\
\hline & Total & $38.3 \pm 33.45$ & $41.3 \pm 13.70$ & \\
\hline \multirow{3}{*}{$\begin{array}{l}\text { Organizational } \\
\text { respect for the } \\
\text { employee }\end{array}$} & Experiment & $27.4 \pm 27.40$ & $29.2 \pm 73.15$ & \multirow{3}{*}{0.003} \\
\hline & Control & $27.3 \pm 00.00$ & $27.2 \pm 13.10$ & \\
\hline & Total & $27.3 \pm 13.70$ & $28.2 \pm 43.47$ & \\
\hline \multirow{3}{*}{$\begin{array}{l}\text { Organizational } \\
\text { employer care }\end{array}$} & Experiment & $24.4 \pm 40.12$ & $30.1 \pm 20.32$ & \multirow{3}{*}{0.003} \\
\hline & Control & $26.3 \pm 13.20$ & $27.2 \pm 73.81$ & \\
\hline & Total & $25.3 \pm 27.73$ & $28.2 \pm 97.50$ & \\
\hline \multirow{3}{*}{$\begin{array}{l}\text { Work into the } \\
\text { private life }\end{array}$} & Experiment & $27.3 \pm 40.20$ & $30.2 \pm 60.97$ & \multirow{3}{*}{0.002} \\
\hline & Control & $28.2 \pm 07.22$ & $27.3 \pm 47.74$ & \\
\hline & Total & $27.2 \pm 73.73$ & $29.3 \pm 03.68$ & \\
\hline \multirow{3}{*}{$\begin{array}{c}\text { Total occupational } \\
\text { wellbeing }\end{array}$} & Experiment & $118.12 \pm 00.21$ & $133.6 \pm 33.65$ & \multirow{3}{*}{0.004} \\
\hline & Control & $118.7 \pm 93.19$ & $121.8 \pm 80.52$ & \\
\hline & Total & $118.9 \pm 47.86$ & $127.9 \pm 57.53$ & \\
\hline
\end{tabular}

As the occupational wellbeing variable consisted of 4 parameters, MANCOVA was used to investigate the above hypothesis. Flourish was considered as an independent variable, participants' scores in post-test as a dependent variable, and their scores in pre-test as a covariate. The covariance test has some assumptions. Thus, it is necessary to investigate variables' normality, regression slope homogeneity, linear relationship, and variances equality of pre-test and post-test scores in the considered variable. Kolmogorov-Smirnov test was used to investigate data normality. Table 2 shows the results.

As presented in the Table 1, the statistic value of the Kolmogorov-Smirnov test in pre-test and post-test scores of occupational wellbeing parameters is observed, and almost all research variables in both groups, as well as pre-test and post-test, were normal. Therefore, the data normality hypothesis was approved. Among the other conditions, the test condition is a linear relationship between pre-test and post-test scores of research variables.

\begin{tabular}{|cccccc|}
\hline Resources & $\begin{array}{c}\text { Sum of } \\
\text { Squares }\end{array}$ & $\begin{array}{c}\text { Degree of } \\
\text { Freedom }\end{array}$ & $\begin{array}{c}\text { Mean } \\
\text { Square }\end{array}$ & F & p-value \\
Group & 0.331 & 1 & 0.331 & 0.003 & 0.940 \\
Pre-test & 142.644 & 1 & 142.644 & 2.504 & 0.126 \\
Group*pre-test & 7.778 & 1 & 7.778 & 0.137 & 0.715 \\
Error & 1481.339 & 26 & 56.975 & - & - \\
\hline Table 2. Regression Slope Homogeneity for Occupational \\
Wellbeing Variable \\
\hline \multicolumn{5}{c}{} \\
\hline \multicolumn{7}{c}{} \\
\hline
\end{tabular}

Referring to the Table 2, the statistic value (0.137) obtained from the test with a p-value $(0.715)$ is more than 0.05 . Therefore, the interaction resulted from the data is not significant. That is, regression slope homogeneity is approved, confirming this hypothesis. After investigating the general hypothesis of covariance analysis, MANCOVA is analysed. MANCOVA has some hypotheses to be investigated. Box's $M$ test is used to examine the equality of variancecovariance matrix, being confirmed by the results (Box's M18.446, F-1.556, P-0.113). Moreover, Levene's test is used to investigate error variances of the test. Table 4 provides the results. 


\begin{tabular}{|c|c|c|c|c|}
\hline Variables & F-statistic & $\begin{array}{c}\text { Intergroup } \\
\text { DF }\end{array}$ & $\begin{array}{c}\text { Intragroup } \\
\text { DF }\end{array}$ & Significance \\
\hline Work satisfaction & 3.002 & 1 & 28 & 0.094 \\
\hline $\begin{array}{l}\text { Organizational respect } \\
\text { for the employee }\end{array}$ & 0.140 & 1 & 28 & 0.711 \\
\hline $\begin{array}{l}\text { Organizational } \\
\text { employer care }\end{array}$ & 4.825 & 1 & 28 & 0.036 \\
\hline $\begin{array}{l}\text { Work into the private } \\
\text { life }\end{array}$ & 1.698 & 1 & 28 & 0.203 \\
\hline
\end{tabular}

According to the Table 3, the assumption of error variances equality and variance-covariance hypothesis is confirmed in occupational wellbeing parameters; therefore, MANCOVA analysis tests show a significant difference in the scores between both groups (Wilk's Lambda-0.711, F-3.732, P-0.019) (Table 5).

\begin{tabular}{|c|c|c|c|c|c|c|}
\hline \multirow{2}{*}{ Traces } & \multirow{2}{*}{ Value } & DF & DF & & \multirow{2}{*}{$\begin{array}{l}\text { Effect } \\
\text { Size }\end{array}$} & \multirow{2}{*}{ Power } \\
\hline & & Hypothe & Error & & & \\
\hline Pillais trace & 0.4153 .732 & 4 & 21 & 0.019 & 0.415 & 0.800 \\
\hline $\begin{array}{l}\text { Wilk's Lambda } \\
\text { trace }\end{array}$ & 05853.732 & 4 & 21 & 0.019 & 0.415 & 0.800 \\
\hline Hotelling's trace & 0.7113 .732 & 4 & 21 & 0.019 & 0.415 & 0.800 \\
\hline $\begin{array}{l}\text { Roy's largest } \\
\text { root }\end{array}$ & 0.7113 .732 & 4 & 21 & 0.019 & 0.415 & 0.800 \\
\hline
\end{tabular}

The results show a significant difference in occupational wellbeing parameters between the two-flourish training and control groups. The results of MANCOVA analysis are represented in the following to show this difference.

\begin{tabular}{|c|c|c|c|c|c|c|c|}
\hline $\begin{array}{c}\text { Statistical } \\
\text { Index Sources }\end{array}$ & $\begin{array}{l}\text { Sum of } \\
\text { Squares }\end{array}$ & DF & $\begin{array}{c}\text { Squares } \\
\text { Mean }\end{array}$ & $\mathbf{F}$ & Significanc & $\begin{array}{c}\text { Eta } \\
\text { Squared }\end{array}$ & Power \\
\hline Work satisfaction & 70.180 & 1 & 70.180 & 5.548 & 0.027 & 0.188 & 0.618 \\
\hline $\begin{array}{l}\text { Organizational } \\
\text { respect for the } \\
\text { employee }\end{array}$ & 43.878 & 1 & 43.878 & 10.423 & 0.004 & 0.303 & 0.872 \\
\hline $\begin{array}{l}\text { Organizational } \\
\text { employer care }\end{array}$ & 29.637 & 1 & 29.637 & 6.079 & 0.021 & 0.202 & 0.658 \\
\hline $\begin{array}{l}\text { Work into the } \\
\text { private life }\end{array}$ & 67.785 & 1 & 67.785 & 5.258 & 0.031 & 0.180 & 0.595 \\
\hline
\end{tabular}

As observed in the above table, there is a significant difference in all four occupational wellbeing parameters between the experiment and control groups. According to Table 4 and descriptive findings, participants' scores increase in occupational wellbeing post-test. Therefore, flourish training increases the occupational wellbeing of participants, confirming the related hypothesis.

\section{DISCUSSION}

The present study aimed to determine the effectiveness of flourish training on occupational well-being. The results showed that flourish training made a significant difference in all research variables between experiment and control groups. It means that the mean of the experiment group has significantly increased compared to the control group, indicating flourish training effectiveness on occupational wellbeing. Our results are consistent with some studies.6,7,8,9

Based on previous studies, all aspects of occupational wellbeing are directly related to well-being. Theoretically, work satisfaction is completely related to self-esteem and other positive emotions. Moreover, positive emotions can enhance self-satisfaction. ${ }^{6}$ Other evidence also showed flourish training included important content which affect positive status in human. Therefore, the content of the plan of the present study determines the major part of explaining the effectiveness and explaining the results obtained. In general, all educational programs that are associated with increasing job efficiency seek to influence the variables that increase positive emotions and psychological well-being. ${ }^{7}$

Evidence suggests that flourish training can increase personal resiliency because the content of this program includes items to increase employee self-esteem. ${ }^{9}$ Moreover, resiliency is a construct that has been studied a lot in the field of job studies and it has been determined that this structure is the basis of personal capabilities and increasing efficiency. So, in explaining the findings of this study, we should take a brief look at the issue of resiliency and self-efficacy. Although in previous studies there is not much mention of intermediate variables, but it seems that we should emphasize the role of resilience and self-efficacy in studies in this area. In sum, people's cognitive abilities and sense of selfefficacy are positive emotions that have been evaluated in positive psychology. With these descriptions, it can be explained that cognitive variables can provide job satisfaction by relying on positive psychology. In positive psychology, a lot of attention has been paid to the positive points of human beings and reinforcing them and this attention and this attention has expanded a lot in the field of occupational flourishing. It is worth to highlight that the more positive emotions develop in a person, the more job well-being appears. So, sense of worth and self-esteem can provide a personal ability to effective and efficient function. Also, in our study, the results confirm previous research evidence and related studies in this field. ${ }^{7}$ Organizational employer care and Work into the private life have been evaluated as the most important factors in job situations. These two factors also play an important role in psychological well-being. ${ }^{6}$ Psychological well-being also has a strong relationship with job well-being and it seems that in the present study, the content of the training program includes tips to increase the job and psychological well-being of employees.

Despite the useful results of this study and the experimental design used, it should be noted that there are limitations such as lack of follow-up period. Besides, the sample included trainers of exceptional children with special Needs in Yazd which may limit the generalizability of the results. Finally, experimental methods have always sought to maximize statistical control, but intervening factors may have influenced the final results. Therefore, it is suggested that in future studies of follow-up periods, strong experimental designs and broader examples of other occupations be used.

\section{CONCLUSIONS}

MANCOVA analysis results show that the absence of negative experiences, such as anxiety and mental pressure, in all occupational wellbeing parameters causes a significant difference between the experiment and control groups. The results are consistent with those of the previous. 
Data sharing statement provided by the authors is available with the full text of this article at jemds.com.

Financial or other competing interests: None.

Disclosure forms provided by the authors are available with the full text of this article at jemds.com.

\section{REFERENCES}

[1] Gilman R, Huebner S. A review of life satisfaction research with children and adolescents. School Psychology Quarterly 2003;18(2):192-205.

[2] Dahl CJ, Wilson-Mendenhall CD, Davidson RJ. The plasticity of well-being: a training-based framework for the cultivation of human flourishing. Proc Natl Acad Sci USA 2020;117(51):32197-206.

[3] Stoeber J, Corr PJ. A short empirical note on perfectionism and flourishing. Personality and Individual Differences 2016;90:50-3.

[4] Jankowski PJ, Sandage SJ, Bell CA, et al. Virtue, flourishing, and positive psychology in psychotherapy: an overview and research prospectus. Psychotherapy (Chic) 2020;57(3):291-309.

[5] Leibow MS, Lee JW, Morton KR. Exercise, flourishing, and the positivity ratio in seventh-day adventists: a prospective study. Am J Health Promot 2021;35(1):4856.

[6] Lambert L, Warren MA, Schwam A, et al. Positive psychology interventions in the United Arab Emirates: boosting wellbeing - and changing culture? Curr Psychol 2021:1-14.

[7] Nelson V, Derrett S, Wyeth E. Indigenous perspectives on concepts and determinants of flourishing in a health and well-being context: a scoping review protocol. BMJ Open 2021;11(2):e045893.

[8] Diener E, Scollon C. Subjective well-being is desirable, but not the summum bonum. University of Minnesota: article présenté à la conférence University of Minnesota Interdisciplinary 2003.

[9] Parker GB, Hyett MP. Measurement of wellbeing in the workplace: the development of the work wellbeing questionnaire. J Nerv Ment Dis 2011;199(6):394-7.

[10] Savitsky B, Radomislensky I, Hendel T. Nurses' occupational satisfaction during Covid-19 pandemic. Appl Nurs Res 2021;59:151416.

[11] Galloway S, Bell D, Hamilton C, et al. Well-being and quality of life: measuring the benefits of culture and sport - a literature review and thinkpiece. Scottish Government 2006.

[12] Kaabomeir N, Naami A. The effect of perceived organizational justice on organizational loyalty and job well-being with mediating role of social undermining and moderating role of job control in employees of Ahwaz Golestan Hospital. Journal of Nursing Education 2016;5(3):55-63.

[13] Yeo SE. Resilience, character strengths and flourishing: a positive education workshop for Singapore teachers. 2011. 